\title{
STUDY OF THE INFLUENCE OF EXPERIMENTAL CONDITIONS ON THE TEMPERATURES OF PHASE TRANSFORMATIONS IN HIGH-TEMPERATURE AREA FOR Fe-C-Cr AND Fe-C-Ni BASED SYSTEMS
}

\author{
${ }^{1}$ L'ubomíra DROZDOVÁ, 'Bedřich SMETANA, 'Mario MACHU゚, ${ }^{1}$ Hana FRANCOVÁ, ${ }^{1}$ Simona ZLÁ, \\ ${ }^{1}$ Vlastimil NOVÁK, ${ }^{1}$ Lenka ŘEHÁČKOVÁ, ${ }^{1}$ Filip RADKOVSKÝ, ${ }^{1}$ Petr LICHÝ \\ ${ }^{1}$ Faculty of materials science and technology, VSB-Technical University of Ostrava, Czech Republic, EU \\ lubomira.drozdova@vsb.cz
}

https://doi.org/10.37904/metal.2019.670

\begin{abstract}
One model alloy based on Fe-C-Cr and one model alloy based on Fe-C-Ni were studied. Fe-C-Cr based alloy contained carbon of $0.34 \mathrm{wt}$. \% and chromium of $0.92 \mathrm{wt}$. \%. Fe-C-Ni based alloy contained carbon of $0.38 \mathrm{wt}$. $\%$ and nickel of $1.08 \mathrm{wt}$. \%. Temperatures of phase transformations (temperature of the solidus, liquidus and peritectic transformation) were studied in the high-temperature area by a heating rate of $1,2,5,10$ and $20^{\circ} \mathrm{C} / \mathrm{min}$., the influence of heating rate was investigated. The influence of the sample mass was also studied by the heating rate of $10^{\circ} \mathrm{C} / \mathrm{min}$. Samples with mass $50,100,190,280$ and $370 \mathrm{mg}$ were studied. Samples with the mass $190 \mathrm{mg}$ were studied by various heating rates. The Setaram Setsys 18тм device was used for experiments with the use of the DTA method. No influence of the heating rate was detected for the temperature of solidus for both alloys. The most significant influence of heating rate was observed for the temperature of liquidus (temperature difference $6-8^{\circ} \mathrm{C}$ ). More noticeable impact of heating rate on the temperature of peritectic transformation shift was observed by $\mathrm{Fe}-\mathrm{C}-\mathrm{Cr}$ based alloy investigation. The influence of sample mass is negligible regarding the temperature of solidus and significant in case of liquids (for both alloys) and peritectic transformation (for $\mathrm{Fe}-\mathrm{C}-\mathrm{Cr}$ alloy) temperature.
\end{abstract}

Keywords: DTA, heating rate, sample mass, temperatures of phase transformations, $\mathrm{Fe}-\mathrm{C}-\mathrm{Cr}$ and $\mathrm{Fe}-\mathrm{C}-\mathrm{Ni}$ based alloys

\section{INTRODUCTION}

Thermo-physical and thermodynamic properties of systems based on Fe were and still are a subject of extensive research [1-3]. To predict thermo-physical and thermodynamic material properties of complex systems is necessary to have a high quality of experimental data of simpler systems such as Fe-C-O, Fe-C-O-Cr or Fe-C-O-Ni $[1,2,4,5]$. The key material data required for the thermodynamic and thermos-physical description of materials include the heat capacities, the phase transformation temperatures, latent heat and others [2].

Temperatures of phase transformations of Fe- based systems (steels) have technological importance and are commonly used as the input data in software packages (e. g. Procast, Magmasoft, ANSYS Fluent). This paper presents results obtained by one of the thermal analysis methods: Differential thermal analysis (DTA) which makes it possible to obtain temperatures of phase transformations [6]. Experimental conditions influence on experimental data obtained by this method. To those belongs heating/cooling rate, the mass of the sample, type and purity of atmosphere during analysis, reference sample [7]. The paper deals with possibilities of elimination of some influences at experiments.

This paper presents the influence of the heating rate and the mass on the sample on temperatures of phase transformations in the high-temperature area (temperature of solidus, liquidus and peritectic transformation). Influence of heating rate of the temperature on liquidus was studied in [8], and influence of the heating rate and mass of the sample of temperatures of phase transformations in the low and high-temperature area was studied in [9]. 


\section{EXPERIMENT}

\subsection{Sample characterization}

One model alloy based on Fe-C-Cr and one model alloy based on Fe-C-Ni were studied. The first alloy contained carbon of $0.34 \mathrm{wt}$. \% and chromium of $0.92 \mathrm{wt}$. \%. The second alloy contained carbon of $0.38 \mathrm{wt}$ \% and nickel of 1.08 wt. \%. Chemical composition that was determined directly on samples for thermal analysis is presented in Table 1.

Table 1 Chemical composition of studied alloys /wt. \%

\begin{tabular}{ccccccccc}
\hline Alloy & $\mathbf{C}$ & $\mathbf{C r}$ & $\mathbf{N i}$ & $\mathbf{O}$ & $\mathbf{P}$ & $\mathbf{S}$ & $\mathbf{M n}$ & Al \\
\hline Fe-C-Cr & 0.344 & 0.924 & 0.001 & 0.002 & 0.004 & 0.007 & 0.056 & 0.010 \\
Fe-C-Ni & 0.382 & 0.010 & 1.084 & 0.002 & 0.004 & 0.005 & 0.030 & 0.010 \\
\hline
\end{tabular}

The samples for DTA analysis were processed into the form of cylinders with a diameter $3.5 \mathrm{~mm}$ and high of 3 $\mathrm{mm}$. The mass of the cylinders was $190 \mathrm{mg}$ for analysis of the influence of the heating rate and 50,100, 190, 280 and $370 \mathrm{mg}$ for analysis of the influence of the mass of the samples. The samples were polished (the possible oxidation layer was removed) and cleaned ultrasonically in acetone before analysis. Temperature calibration was performed using Pd for all alloys.

\subsection{Experimental conditions}

For obtaining the temperatures of phase transformations with the help of Differential Thermal Analysis (DTA) was used Setaram Setsys $18 \mathrm{TM}$. The measurements were carried out in alumina crucibles with a volume of 80 $\mu \mathrm{l}$. An empty corundum crucible served as a reference sample. The dynamic atmosphere of argon was maintained in the furnace during analysis to protect the sample against oxidation. The purity of argon was higher than $99.9999 \%$. Samples for the influence of heating rate were analysed at the heating rate of 1, 2, 5, 10 and $20^{\circ} \mathrm{C} / \mathrm{min}$. The samples for the influence of mass were analysed with the heating rate of $10^{\circ} \mathrm{C} / \mathrm{min}$.

\section{RESULTS AND DISCUSSION}

Temperatures of phase transformations in the high-temperature area were obtained based on the evaluation of DTA curves. Temperatures of solidus $(T s)$, liquidus $\left(T_{L}\right)$ and peritectic transformation $\left(T_{P}\right)$ were detected. Measured DTA curves of five experimental measurements for the influence of heating rate on shifting of temperatures of phase transformations are in Figure 1 and Figure 2. Experimental values with the correction to $\mathrm{Pd}$ for this influence are in Table 2 and Table 3. Measured DTA curves of five experimental measurements for the influence of the mass of the sample on shifting of temperatures of phase transformations are in Figure 3 and Figure 4. Experimental values with the correction to Pd for this influence are in Table $\mathbf{4}$ and Table $\mathbf{5}$. Tables also present the statistical data (average, standard deviation and coefficient of variation $\mathrm{CV}$ ) obtained from the measured values [10].

\subsection{Influence of heating rate on shifting of temperatures of phase transformations}

From Table 2 and Table 3 can be seen the influence of heating rate on all temperatures measured by DTA method. All temperatures are shifted with the increased heating rate to the higher values except for the temperature of solidus. For $\mathrm{Fe}-\mathrm{C}-\mathrm{Cr}$ alloy the smallest influence of heating rate is for temperature of solidus (Table 2; $\mathrm{T}_{\mathrm{MAX}}-\mathrm{T}_{\mathrm{MIN}}=5{ }^{\circ} \mathrm{C}, \mathrm{CV}=0.11 \%$ ). The greater influence of heating rate is for temperature of liquidus (Table 2; $\mathrm{T}_{\mathrm{MAX}}-\mathrm{T}_{\mathrm{MIN}}=6{ }^{\circ} \mathrm{C}, \mathrm{CV}=0.15 \%$ ). The biggest influence is clear for temperature of peritectic transformation (Table 2; $\mathrm{T}_{\mathrm{MAX}}-\mathrm{T}_{\mathrm{MIN}}=7{ }^{\circ} \mathrm{C}, \mathrm{CV}=0.17 \%$ ). For Fe-C-Ni alloy was not detected the temperature of peritectic transformation for all heating rates because the difference between $T_{P}$ and $T_{L}$ is very small and by higher heating rates effect of peritectic transformation merged with melting. Influence of heating rate for heating rates $1-5{ }^{\circ} \mathrm{C} / \mathrm{min}$ is not detected for temperature of solidus (Table $3 ; \mathrm{T}_{\mathrm{MAX}}-\mathrm{T}_{\mathrm{MIN}}=1{ }^{\circ} \mathrm{C}$ ). By heating rates 10 
and $20{ }^{\circ} \mathrm{C} / \mathrm{min}$ with increasing heating rate increase temperature of solidus (Table $3 ; \mathrm{T}_{\mathrm{MAX}}-\mathrm{T}_{\mathrm{MIN}}=4{ }^{\circ} \mathrm{C}$ ). The biggest influence is clear for temperature of liquidus (Table 3; $\mathrm{T}_{\mathrm{MAX}}-\mathrm{T}_{\mathrm{MIN}}=8{ }^{\circ} \mathrm{C}, \mathrm{CV}=0.21 \%$ ).

Table 2 Influence of heating rate to temperatures of phase transformations of $\mathrm{Fe}-\mathrm{C}-\mathrm{Cr}$ alloy

\begin{tabular}{cccc}
\hline Heating rate & $\mathrm{T}_{\mathrm{S}}$ & $\mathrm{T}_{\mathrm{P}}$ & $\mathrm{T}_{\mathrm{L}}$ \\
\hline$\left({ }^{\circ} \mathrm{C} / \mathrm{min}\right)$ & & $\left({ }^{\circ} \mathrm{C}\right)$ & \\
\hline $\mathbf{1}$ & 1439 & 1494 & 1510 \\
$\mathbf{2}$ & 1439 & 1495 & 1510 \\
$\mathbf{5}$ & 1436 & 1496 & 1512 \\
$\mathbf{1 0}$ & 1441 & 1499 & 1513 \\
$\mathbf{2 0}$ & 1438 & 1501 & 1516 \\
$\mathbf{0}$ & 1439 & $\mathbf{1 4 9 3}$ & $\mathbf{1 5 1 0}$ \\
\hline & $\mathbf{S t a t i s t i c}$ & \\
\hline Average & 1439 & 1497 & 1512 \\
$\mathrm{~T}_{\text {MIN }}$ & 1436 & 1494 & 1510 \\
$\mathrm{~T}_{\text {MAX }}$ & 1441 & 1501 & 1516 \\
$\Delta \mathrm{T}_{\text {MAX }} \mathrm{T}_{\text {MIN }}$ & 5 & 7 & 6 \\
St. deviation & 1.62 & 2.61 & 2.23 \\
CV $(\%)$ & 0.11 & 0.17 & 0.15 \\
\hline
\end{tabular}

Table 3 Influence of heating rate to temperatures of phase transformations of Fe-C-Ni alloy

\begin{tabular}{cccc}
\hline Heating rate & $\mathrm{T}_{\mathrm{S}}$ & $\mathrm{T}_{\mathrm{P}}$ & $\mathrm{T}_{\mathrm{L}}$ \\
\hline$\left({ }^{\circ} \mathrm{C} / \mathrm{min}\right)$ & & $\left({ }^{\circ} \mathrm{C}\right)$ & \\
\hline $\mathbf{1}$ & 1441 & 1502 & 1506 \\
$\mathbf{2}$ & 1440 & 1503 & 1506 \\
$\mathbf{5}$ & 1441 & 1505 & 1508 \\
$\mathbf{1 0}$ & 1443 & - & 1511 \\
$\mathbf{2 0}$ & 1447 & - & 1514 \\
$\mathbf{0}$ & $\mathbf{1 4 4 0}$ & $\mathbf{1 5 0 1}$ & $\mathbf{1 5 0 5}$ \\
\hline & Statistic & & \\
\hline Average & 1442 & 1503 & 1509 \\
$\mathrm{~T}_{\text {MIN }}$ & 1440 & 1502 & 1506 \\
$\mathrm{~T}_{\text {MAX }}$ & 1447 & 1505 & 1514 \\
$\Delta \mathrm{T}_{\text {MAX }} \mathrm{T}_{\text {MIN }}$ & 7 & 3 & 8 \\
St. deviation & 2.50 & 1.25 & 3.10 \\
$\mathbf{C V}$ (\%) & 0.17 & 0.08 & 0.21 \\
\hline
\end{tabular}

Based on DTA results, a regression dependence of the heating rate influence for all temperatures of phase transformations was developed (Figure 1 and Figure 2). In the charts, the reliability value R2 is shown for completeness. The obtained values of $T_{S}, T_{P}$ and $T_{L}$ were extrapolated to the "zero" heating rate, and these values are also given in Table 2 and Table 3. Based on the obtained dependences, it is possible to correct the data $\left(T s, T_{P}, T_{L}\right)$ obtained for other investigated Fe-based metallic systems, such as steels, to the "zero" heating rate. We can thus obtain for the investigated systems the temperatures close to equilibrium temperatures, without time-consuming experimental measurements.

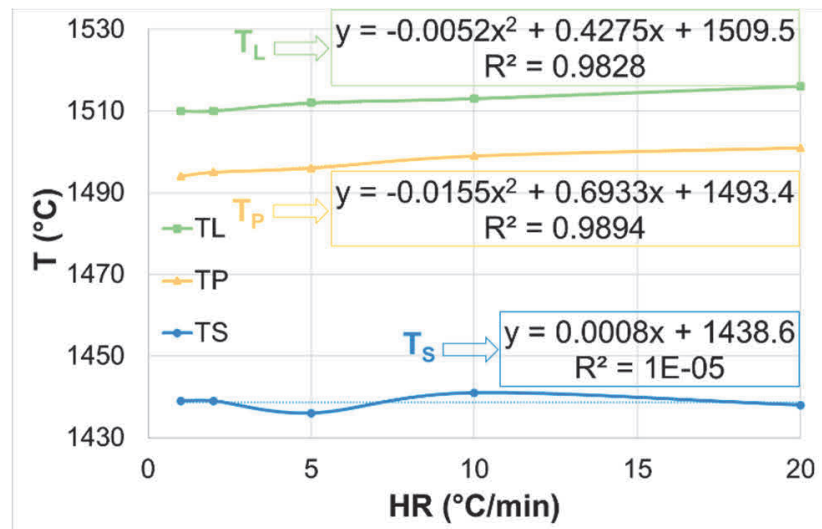

Figure 1 Regression dependence of heating rate for Fe-C-Cr alloy

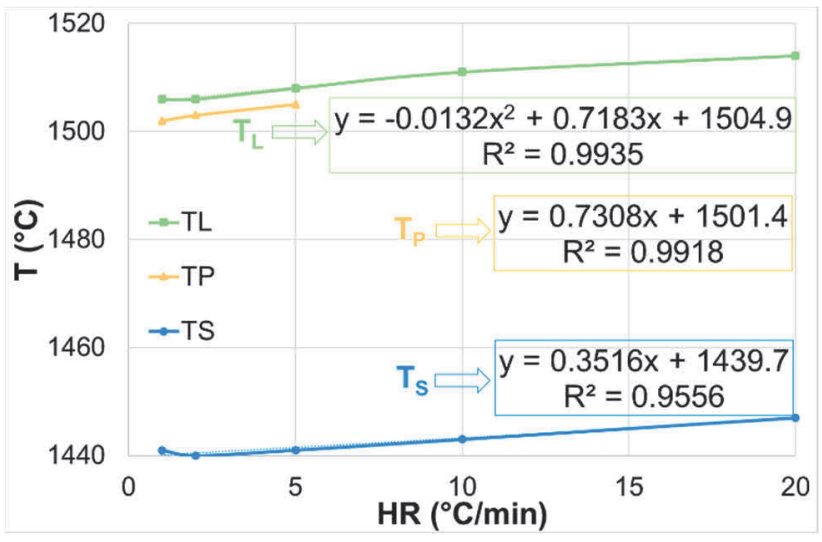

Figure 2 Regression dependence of heating rate for Fe-C-Ni alloy

The shift of temperatures to higher values with the increasing rate can be explained in method DTA by dynamics of the process and by detection capabilities of instruments. Different heating rates can also have a significant effect on the kinetics of phase transformations (transition mechanism) [8,9]. 


\subsection{Influence of the mass of the sample on shifting of temperatures of phase transformations}

From Table 4 and Table 5 can be seen the influence of the mass of the sample on shifting all temperatures measured by DTA method. The smallest influence of the mass is detected for temperature of solidus for both alloys $\left(\mathrm{T}_{\mathrm{MAX}}-\mathrm{T}_{\mathrm{MIN}}=4-5{ }^{\circ} \mathrm{C}, \mathrm{CV}=0.09-0.13 \%\right)$. The temperature of the peritectic transformation was not detected for mass $50-190 \mathrm{mg}$. The influence of the mass for the temperature of peritectic transformation of Fe-C-Cr alloy and liquidus temperature of both alloy is very close $\left(\mathrm{T}_{\mathrm{MAX}}-\mathrm{T}_{\mathrm{MIN}}=7-8{ }^{\circ} \mathrm{C}, \mathrm{CV}=0.17-0.19 \%\right)$.

Table 4 Influence of the mass to temperatures of phase transformations of $\mathrm{Fe}-\mathrm{C}-\mathrm{Cr}$ alloy

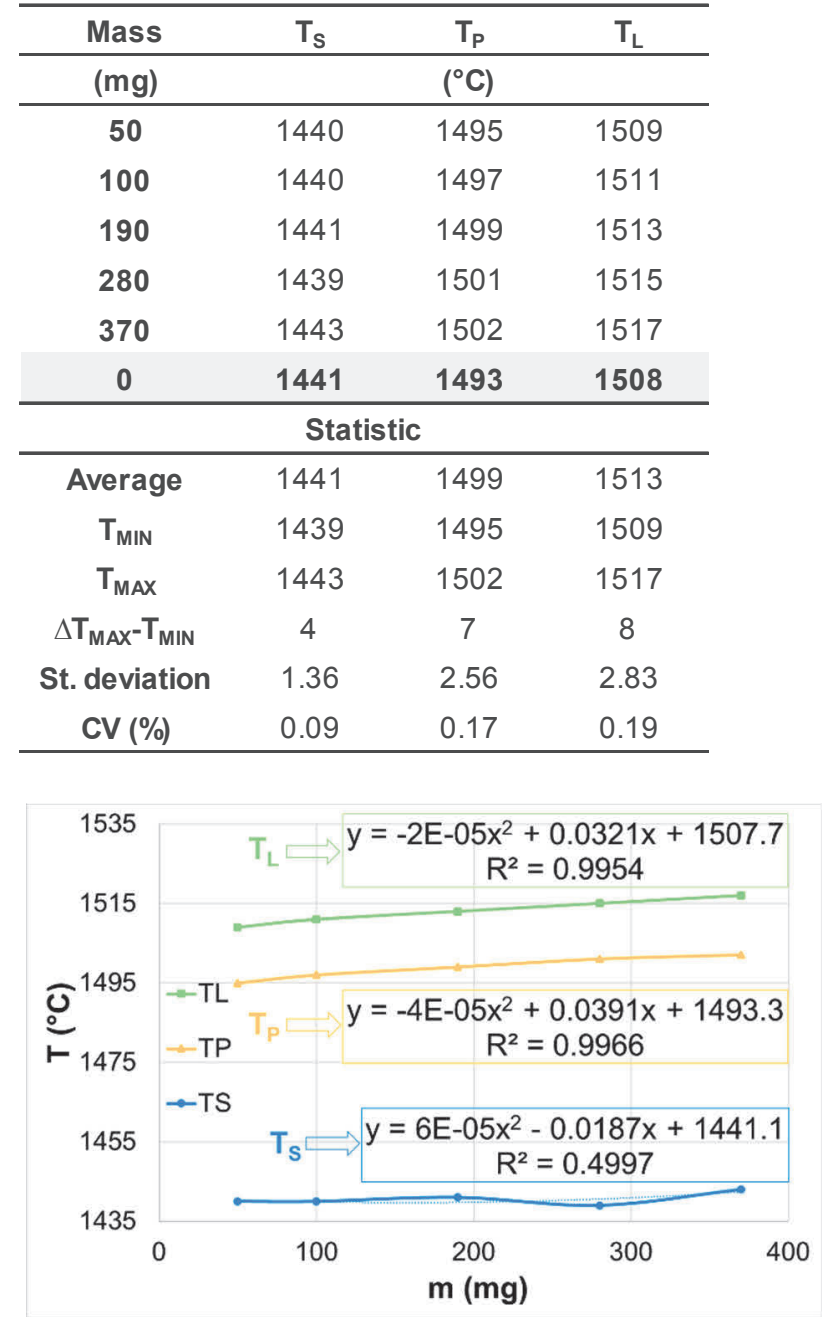

Figure 3 Regression dependence of the mass for Fe-C-Cr alloy
Table 5 Influence of the mass to temperatures of phase transformations of Fe-C-Ni alloy

\begin{tabular}{cccc}
\hline Mass & $\mathrm{T}_{\mathrm{S}}$ & $\mathrm{T}_{\mathrm{P}}$ & $\mathrm{T}_{\mathrm{L}}$ \\
\hline $\mathbf{( m g )}$ & & $\left({ }^{\circ} \mathrm{C}\right)$ & \\
\hline $\mathbf{5 0}$ & 1440 & - & 1506 \\
$\mathbf{1 0 0}$ & 1440 & - & 1509 \\
$\mathbf{1 9 0}$ & 1443 & - & 1511 \\
$\mathbf{2 8 0}$ & 1443 & 1511 & 1513 \\
$\mathbf{3 7 0}$ & 1445 & 1511 & 1514 \\
$\mathbf{0}$ & $\mathbf{1 4 3 9}$ & - & $\mathbf{1 5 0 4}$ \\
\hline \multicolumn{5}{c}{ Statistic } \\
\hline Average & 1442 & 1511 & 1511 \\
$\mathbf{T}_{\text {MIN }}$ & 1440 & 1511 & 1506 \\
$\mathbf{T}_{\text {MAX }}$ & 1445 & 1511 & 1514 \\
$\Delta \mathbf{T}_{\text {MAX }} \mathbf{T}_{\text {MIN }}$ & 5 & 0 & 8 \\
St. deviation & 1.94 & 0.00 & 2.87 \\
CV (\%) & 0.13 & 0.00 & 0.19 \\
\hline
\end{tabular}

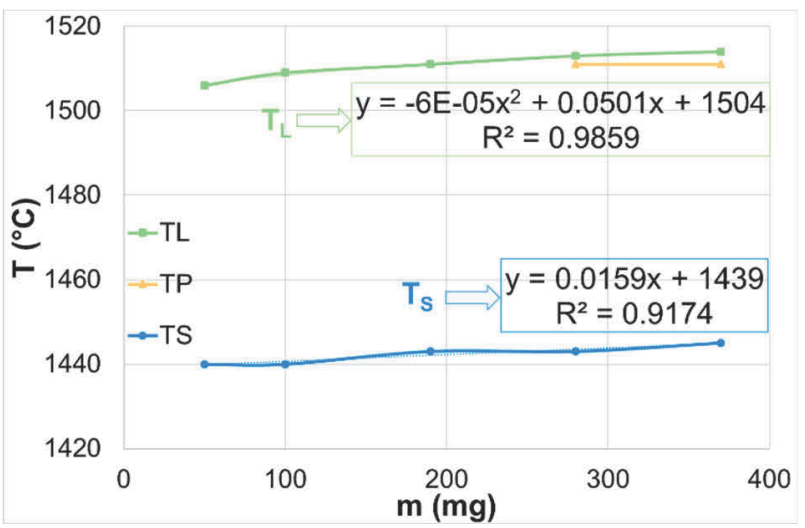

Figure 4 Regression dependence of the mass for Fe-C-Ni alloy

Based on DTA results, a regression dependence of the mass of the sample influence for all temperatures of phase transformations was developer except for the temperature of peritectic transformation for Fe-C-Ni alloy (Figure 3 and Figure 4). In the charts, the reliability value R2 is shown for completeness. The obtained values of $T_{S}, T_{P}$ and $T_{L}$ were extrapolated to the "zero" mass of the sample, and these values are also given in Table 4 and Table 5. On the basis of the obtained dependences, it is possible to correct the data $\left(T_{S}, T_{P}, T_{L}\right)$ obtained for other investigated Fe-based metallic systems, such as steels, to the "zero" mass of the sample

The shift to higher temperatures with the increasing mass can be explained by the fact that the larger sample requires more heat for the phase transformation, and that the phase transformation takes place over a longer 
period of time (i.e. that phase transformation of the larger sample will be terminated only at higher temperature) [9].

Table 6 Comparison of experimental and theoretical temperatures of phase transformations

\begin{tabular}{cccc}
\hline System & $\mathrm{T}_{\mathrm{S}}$ & $\mathrm{T}_{\mathrm{P}}$ & $\mathrm{T}_{\mathrm{L}}$ \\
\cline { 2 - 4 } & \multicolumn{3}{c}{$\left({ }^{\circ} \mathrm{C}\right)$} \\
\hline $\mathrm{Fe}-\mathrm{Fe}_{3} \mathrm{C}$ (0.34 wt. \% C) & 1462 & 1495 & 1511 \\
Fe-C-Cr (0.34 wt. \% C, 0.92 wt. \% Cr) & 1440 & 1493 & 1509 \\
Fe-Fe ${ }_{3}$ C (0.38 wt. \% C) & 1457 & 1495 & 1508 \\
Fe-C-Ni (0.38 wt. \% C, 1.08 wt. \% Ni) & 1440 & 1501 & 1505 \\
\hline
\end{tabular}

The obtained results corrected to the "zero" heating rate and "zero" mass were compared with temperatures

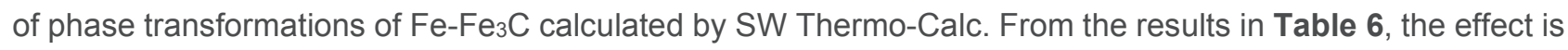
not detected the impact of chromium and nickel to the shift of solidus temperature. For the temperature of peritectic transformation nickel, which shifts this temperature to higher values, has greater influence. Nickel and chromium have approximately the same influence to shifting of the liquidus temperature to lower values.

\section{CONCLUSIONS}

The influence of the heating rate and mass of the sample on the temperatures of phase transformations in the high-temperature area was studied by DTA method.

No influence of the heating rate and mass was detected for the temperature of solidus for both alloys. Temperature range of "zero" values is $1439-1441^{\circ} \mathrm{C}$. It is clear that chromium and nickel do not influence to shifting of this temperature. "Zero" value of the temperature of peritectic transformation was for $\mathrm{Fe}-\mathrm{C}-\mathrm{Cr}$ alloy the same for the influence of the heating rate and mass of the sample $\left(1493{ }^{\circ} \mathrm{C}\right)$. This temperature was detected for the heating rate of Fe-C-Ni alloy $1501{ }^{\circ} \mathrm{C}$ (for the mass was detected only two values; it is not representative). It is clear that chromium decreases $T_{P}$ and nickel has the opposite effect. "Zero" values of temperature of liquidus for $\mathrm{Fe}-\mathrm{C}-\mathrm{Cr}$ alloy are in the range of $1508-1510^{\circ} \mathrm{C}$. Temperature interval for Fe-C-Ni alloy is $1504-1505^{\circ} \mathrm{C}$. It is clear that chromium and nickel shift liquidus temperature to lower values.

On the basis of the obtained dependences that express the influence of the mass of the sample and the heating rate, it is possible to correct the data obtained for other investigated Fe-based metallic systems, such as steel, to the "zero" mass and "zero" heating rate. We can thus obtain for the investigated systems the temperatures close to equilibrium temperatures, without time-consuming experimental measurements.

It is necessary to know the influence of experimental conditions for each experimental device for the measurement of temperatures of phase transformations and minimise.

\section{ACKNOWLEDGEMENTS}

This paper was supported in the frame of GAČR reg. no. 17-18668S project solution and students projects SP2019/90, SP2019/74, SP2019/43 (Faculty of Materials Science and Technology) and "Support of gifted students of doctoral studies at VŠB-TUO" no.: 04766/2017 / RRC (MoravianSilesian Region).

\section{REFERENCES}

[1] KJELLQVIST, Lina and SELLEBY, Malin. Thermodynamic assessment of the Fe-Mn-O system. Journal of phase equilibria and diffusion. 2010. vol. 31, no. 2, pp.113-134. 
[2] MIETTINEN, J. Solidification analysis package for steels-user's manual of DOS version. Laboratory of Metallurgy. Helsinki University of Technology, 1999.

[3] KJELLQVIST, Lina and SELLEBY, Malin. Adding C to the thermodynamic description of the Cr-Fe-Ni-O system. CALPHAD. 2009. vol. 33, no. 2, pp. 393-397.

[4] TAYLOR, Jeffrey, R. and DINSDALE, Alan, T. Thermodynamic assessment of the Cr-Fe-O system. Zeitschriftfuer Metallkunde/Materials Research and Advanced Techniques. 1993. vol. 84, no. 5, pp. 335-345.

[5] LAHEIJ, Majt, A., J., TH., van LOO, F., J., J., and METSELAAR, R. Phase relations in the Fe-Cr-O system at $1200{ }^{\circ} \mathrm{C}$ investigated by means of a diffusion couple technique. Oxidation of Metals [online]. 1980. vol. 14, iss.. 3, pp. 207-215 [viewed 2019-04-25]. Available from: DOI: 10.1007/BF00604564.

[6] GALLAGHER, Patrick, K. Handbook of thermal analysis and calorimetry: principles and practice. 2nd ed. Oxford: Elsevier, 2003. p. 675.

[7] BOETTINGER, W.J., KATTNER, U.R., MOON, K.W. and PEREPEZKO, J.H. DTA and Heat-flux DSC measurements of alloy melting and freezing. Special Publication 960-15. Washington: National Institute of Standards and Technology, 2006. p. 90.

[8] ZLÁ, S., KAWULOKOVÁ, M., DROZDOVÁ, L'., SMETANA, B., DOBROVSKÁ, J., VONTOROVÁ, J., VÁŇOVÁ, P. and JANALÍKOVÁ, V. Influence of heating rate on the liquidus temperature measured by DTA method for $\mathrm{Fe}-\mathrm{C}-\mathrm{Cr}$ based systems. In METAL 2017: 26rd International Conference on Metallurgy and Materials. Ostrava: TANGER, 2017, pp. 139-144.

[9] ŽAlUDOVÁ, M., SMETANA, B., ZLÁ, S., DOBROVSKÁ, J., ROSYPALOVÁ, S., PETLÁK, D., SZURMAN, I. and ŠTVRTŇOVÁ, A. Influence of experimental conditions on data obtained by thermal analysis methods. In METAL 2013: 22rd International Conference on Metallurgy and Materials. Ostrava: TANGER, 2013, pp. 585-591.

[10] PAVLÍK, Jiří. Applied statistics (in Czech). 1st ed. Praha: Vysoká škola chemicko-technologická v Praze, 2005. p. 173. 